Highly impact-resistant block polymer-based thermoplastic elastomers with ionically-functionalized rubber phase

Takato Kajita ${ }^{1}$, Atsushi Noro ${ }^{1,2 *}$, Ryoji Oda $^{3}$, and Sadaharu Hashimoto ${ }^{3}$

${ }^{1}$ Department of Molecular \& Macromolecular Chemistry, Graduate School of Engineering, Nagoya University, Furo-cho, Chikusa-ku, Nagoya 464-8603, Japan

*E-mail: noro@nagoya-u.jp

${ }^{2}$ Institute of Materials Innovation, Institutes of Innovation for Future Society, Nagoya University, Furo-cho, Chikusa-ku, Nagoya 464-8601, Japan

${ }^{3}$ Zeon Corporation, 1-6-2 Marunouchi, Chiyoda-ku, Tokyo 100-8246, Japan 


\section{Synthesis of h-SIS}

h-SIS (Figure S1) was synthesized as previously reported ${ }^{1}$. A typical synthetic procedure is as follows. First, $300 \mathrm{~g}$ (mole of isoprene monomeric units: 3.6 mol) neat SIS (Quintac 3440 of Zeon Corporation; the number-average molecular weight estimated by GPC is $150 \mathrm{k}$, and weight fraction of polystyrene is $19 \mathrm{wt} \%), 112.5 \mathrm{~g}(1.1 \mathrm{~mol})$ maleic anhydride $(\mathrm{TCI})$, the $0.5 \mathrm{~g}$ antioxidant agent of $N$-(1,3-dimethylbutyl)- $N$ '-phenyl-1,4-phenylenediamine (TCI), and $900 \mathrm{~g}$ of cyclohexane were mixed. Then, the solution was heated to approximately $180^{\circ} \mathrm{C}$ and stirred at $50 \mathrm{rpm}$ while keeping the internal pressure of $\sim 1 \mathrm{MPa}$ for about 3 hours. Second, $84 \mathrm{~g}(1.1 \mathrm{~mol}$, an equimolar amount of the maleic anhydride used in the above reaction) of $n$-butylamine (TCI) of was added to the reactive mixture, which was stirred overnight at $50{ }^{\circ} \mathrm{C}$ and $300 \mathrm{rpm}$. The obtained crude product was dissolved in THF, which was added into a large amount of methanol to purify and precipitate h-SIS.

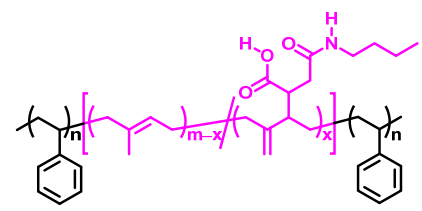

Figure S1. Chemical structure of h-SIS. 
Photo of the GFRP plate.

Figure S2 shows the GFRP plate (PGE-6635, Ryoden Kasei Co., Ltd) with a length of 50 $\mathrm{mm}$, width of $100 \mathrm{~mm}$, and thickness of $4 \mathrm{~mm}$. The GFRP plate was used as a support plate for the drop weight impact test.

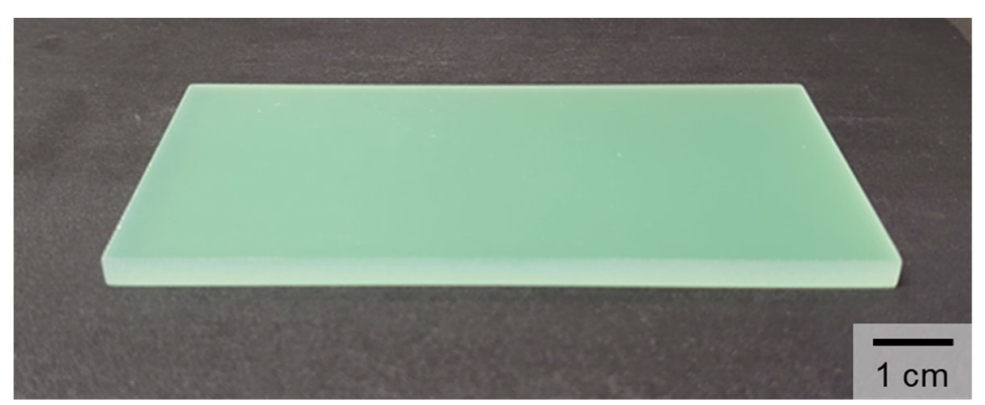

Figure S2. Photo of the GFRP plate. 


\section{${ }^{1}$ H NMR spectrum of neat SIS and succinic anhydride incorporated-SIS, and GPC chromatogram of neat SIS.}

Figure S3a shows the ${ }^{1} \mathrm{H}$ NMR spectra of neat SIS and succinic anhydride incorporated-SIS. The ${ }^{1} \mathrm{H}$ NMR measurement was carried out with Ascend $500 \mathrm{MHz}$ (Bruker). Deuterated chloroform was used as a solvent. Figure S3b shows partial chemical structures of neat SIS and succinic anhydride incorporated-SIS. The peaks at 6.2 to $7.2 \mathrm{ppm}, 4.9$ to $5.3 \mathrm{ppm}$, and 4.5 to 4.9 ppm originate from five protons $\left(\mathrm{H}^{\mathrm{a}}, \mathrm{H}^{\mathrm{a}^{\prime}}\right.$ and $\left.\mathrm{H}^{\mathrm{a}}\right)$ on the phenyl groups of the polystyrene, one proton $\left(\mathrm{H}^{\mathrm{b}}\right)$ on the double bond of the 1,4-polyisoprene, and two protons $\left(\mathrm{H}^{\mathrm{c}}\right.$ and $\left.\mathrm{H}^{\mathrm{c}}\right)$ on the double bond of the 3,4-polyisoprene, respectively. The mole fraction of the polystyrene block in neat SIS was determined to be 0.13 by comparing the integral of protons on polystyrene and that of protons on polyisoprene; thus, the weight fraction of the polystyrene block in neat SIS was estimated to be 0.19. After the reaction between neat SIS and maleic anhydride, the new peaks in the ${ }^{1} \mathrm{H}$ NMR spectrum appeared at 2.3-3.5 ppm originating from three protons $\left(\mathrm{H}^{\mathrm{d}}\right.$ and $\left.\mathrm{H}^{\mathrm{e}}\right)$ on the succinic anhydride units and one proton $\left(\mathrm{H}^{\mathrm{f}}\right)$ on the carbon atom adjacent to the succinic anhydride units. By comparing the integral value of at $2.3-3.5 \mathrm{ppm}$ and the integral one at $4.5-5.3 \mathrm{ppm}$, the mole fraction of succinic anhydride units was estimated to be $5.1 \mathrm{~mol} \%{ }^{1}$

Figure S3c shows the GPC chromatogram of neat SIS. The GPC measurement was carried out with using three TSKgel G4000H Shimadzu), column oven (CTO-20A, Shimadzu) and UV detector (SPD-20A, Shimadzu SPD20A) where the wavelength of UV was $254 \mathrm{~nm}$. The eluent solvent, flow rate, and temperature were tetrahydrofuran, $1.0 \mathrm{~mL} \mathrm{~min}{ }^{-1}$, and $40{ }^{\circ} \mathrm{C}$, respectively. By calibrating molecular weight with polystyrene standards, the number average molecular weight of neat SIS was determined to be $150 \mathrm{k}$. 
(a)

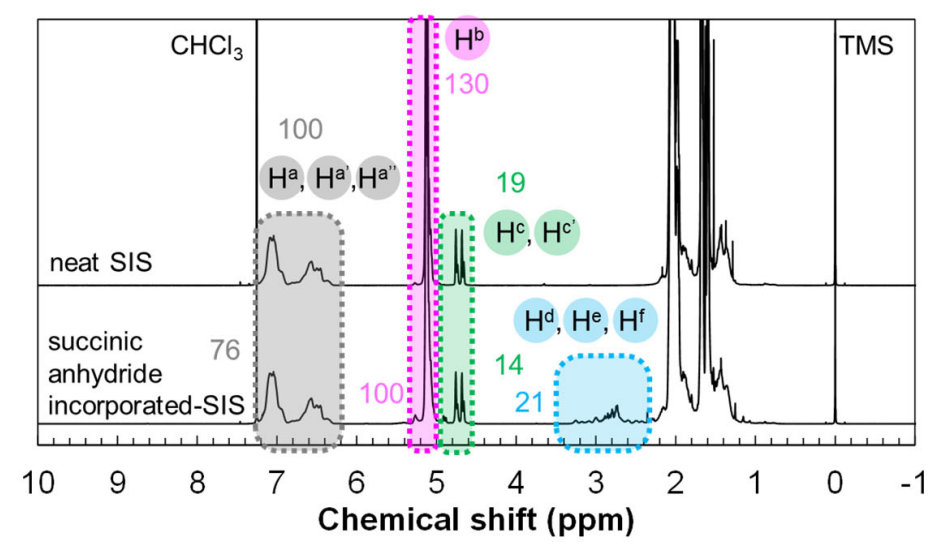

(b)

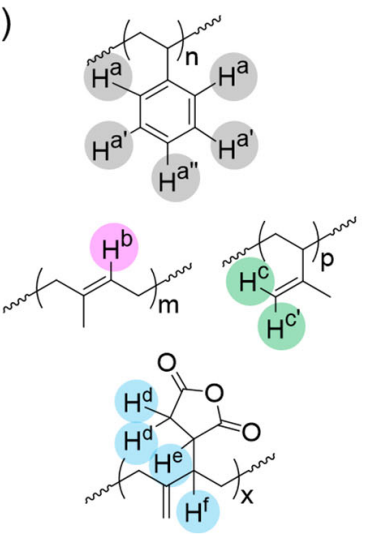

(c)

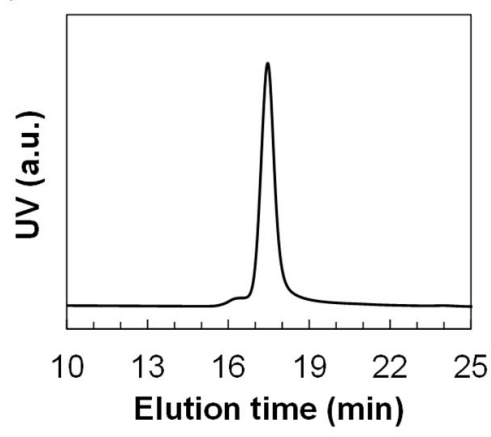

Figure S3. (a) ${ }^{1} \mathrm{H}$ NMR spectra and (b) partial chemical structures of neat SIS and succinic anhydride incorporated-SIS. ${ }^{1}$ Values in the ${ }^{1} \mathrm{H}$ NMR spectra are integral ratio of the peaks. (c) GPC chromatogram of neat SIS. Reprinted in part with permission from ref. 1. Copyright 2021 Elsevier. 


\section{Weight content of the glass fiber in the GFRP.}

Thermogravimetric analysis (TGA) was carried out with Shimadzu DTG-60AH to quantify a weight content of the glass fiber in the GFRP. The experiment was carried out in the range of 25 to $800{ }^{\circ} \mathrm{C}$ at a heating rate of $10{ }^{\circ} \mathrm{C} \mathrm{min}^{-1}$. Air was used as the purge gas, where a flow rate was a

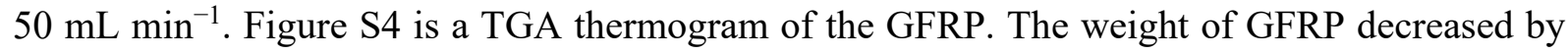
approximately $30 \mathrm{wt} \%$ at higher temperatures, where the organic materials such as epoxy resin in GFRP are burnt out; therefore, the residual weight $(\sim 70 \mathrm{wt} \%)$ is the weight of non-flammable aluminaborosilicate glass fiber in GFRP.

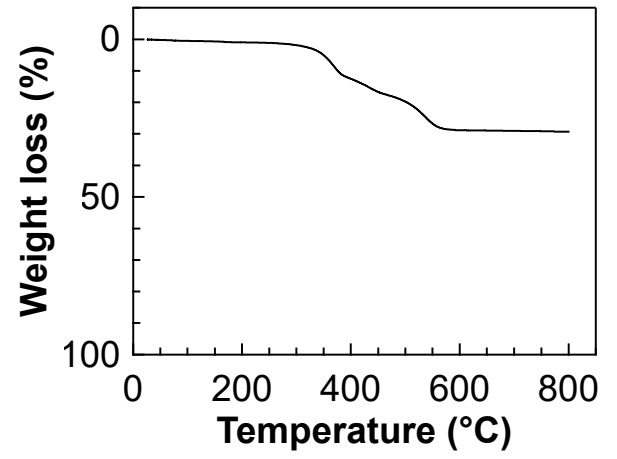

Figure S4. TGA thermogram of the GFRP. 


\section{Synthetic scheme of i-SIS(Na) and i-SIS(Ba).}

Figure S5 is synthetic scheme of i-SIS(Na) and i-SIS(Ba). Details of the scheme are described in an Experimental section.

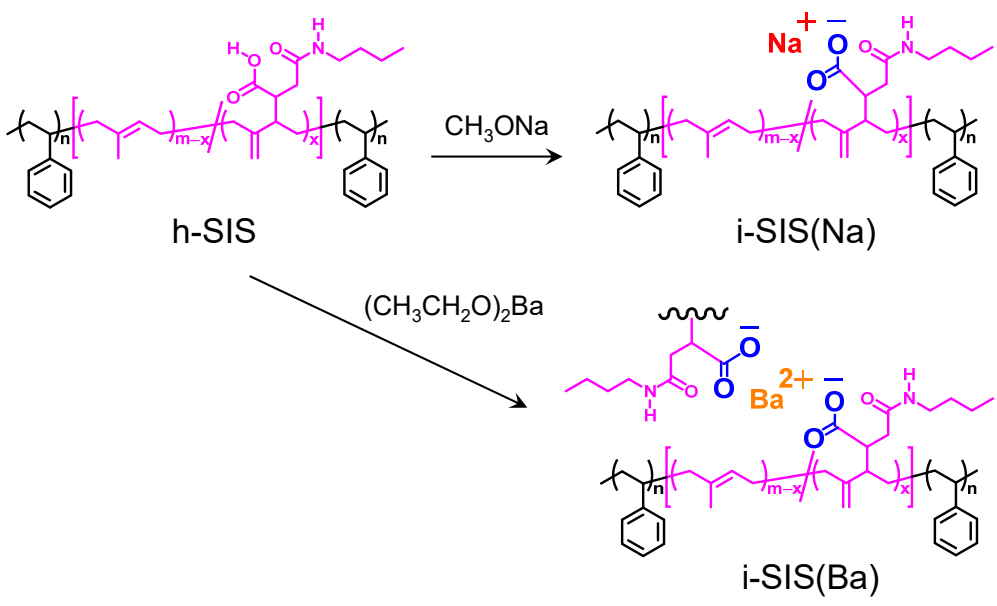

Figure S5. Synthetic scheme of i-SIS(Na) and i-SIS(Ba). 


\section{Small-angle X-ray scattering (SAXS) measurement.}

Nanostructure of i-SIS(Ba) was investigated by a SAXS measurement with an instrument of Nano-Viewer (Rigaku). The wavelength of the X-ray was $0.1542 \mathrm{~nm}$. An imaging plate was used as a detector, and the camera length was $760 \mathrm{~mm}$. The solution-cast film annealed at $150{ }^{\circ} \mathrm{C}$ for 1 day was used for the measurement. Figure S6 shows a small-angle X-ray scattering (SAXS) diffraction pattern of i-SIS(Ba). The intensity was fairly low probably because X-ray was absorbed by heavy barium cation in i-SIS(Ba). A scattering peak at around $1.4 \mathrm{~nm}^{-1}$ probably derived from ionic aggregation. ${ }^{2,3}$

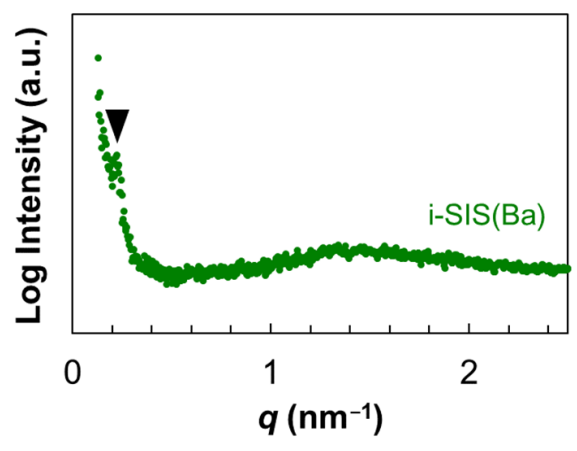

Figure S6. Small-angle X-ray scattering (SAXS) profile of i-SIS(Ba). 
Specimen shape and dimension for various measurements.

(a)

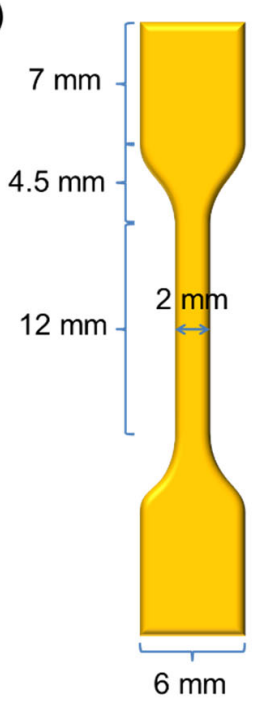

(b)

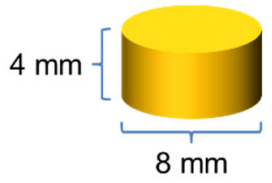

(c)

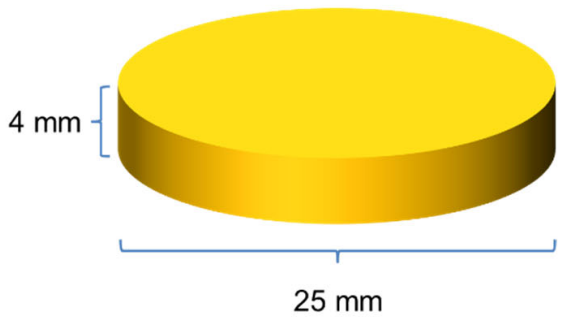

Figure S7. Specimen shape and dimension for (a) tensile, (b) compression, and (c) drop weight impact tests. 
Frequency dependence of storage moduli, $G$ ', and loss moduli, $G$ ”.

Figure S8 shows $G$ ' and $G$ "' of neat SIS, CB-filled NR, i-SIS(Na), and i-SIS(Ba) against frequency at ambient temperature, where the applied strain was $1 \%$ and the angular frequency range was from $10^{2}$ to $10^{-3} \mathrm{rad} \mathrm{s}^{-1}$.
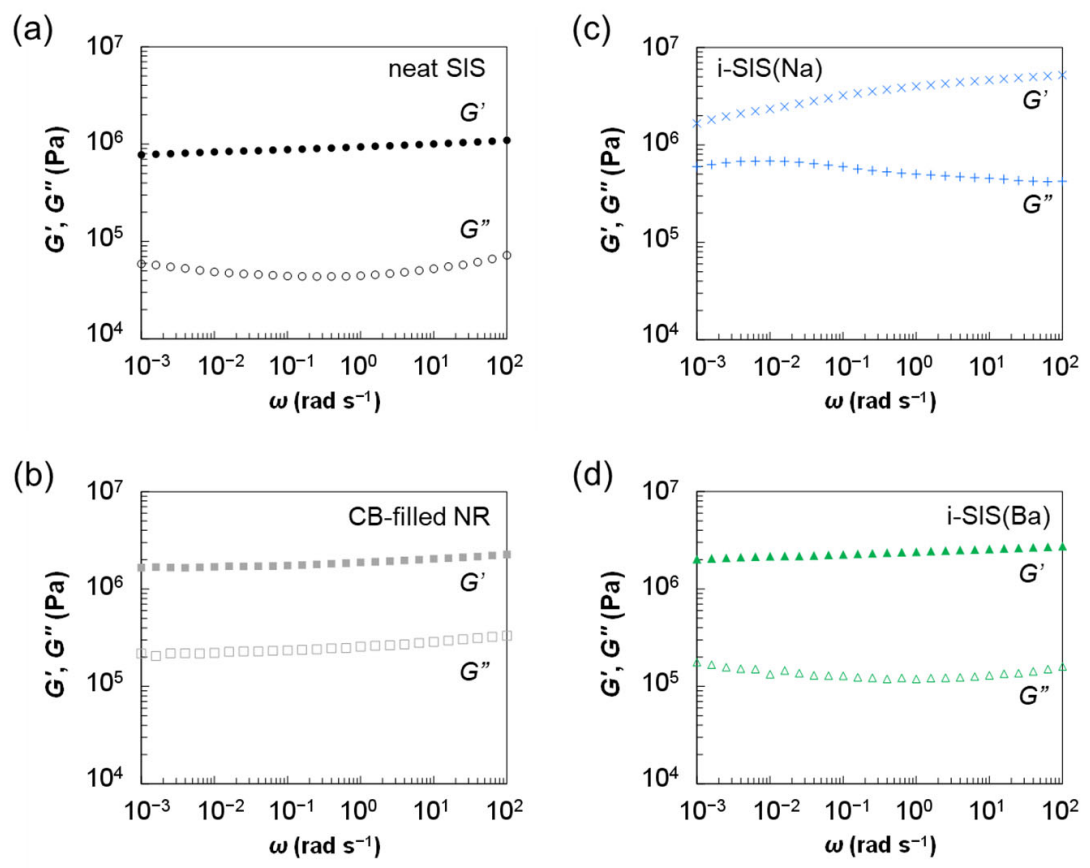

Figure S8. The frequency dependence of $G^{\prime}$ and $G$ " acquired by dynamic mechanical tests for (a) neat SIS, (b) CB-filled NR, (c) i-SIS(Na) and (d) i-SIS(Ba). 


\section{Temperature dependence of $G^{\prime}, G^{\prime}$ and $\tan \delta$.}

Figure S9 shows $G^{\prime}, G^{\prime \prime}$ and $\tan \delta$ of neat SIS, CB-filled NR, i-SIS(Na), and i-SIS(Ba) against temperature, where the applied strain, the angular frequency and the heating rate were $1 \%$, $1 \mathrm{rad} \mathrm{s}^{-1}$ and $2{ }^{\circ} \mathrm{C} \mathrm{min}{ }^{-1}$, respectively. Broad tan $\delta$ peaks are newly observed at around $70{ }^{\circ} \mathrm{C}$ and $85{ }^{\circ} \mathrm{C}$ in ionically-functionalized i-SIS(Na) and i-SIS(Ba), respectively, indicating that there is a relaxation mode originating from optimization of ionic multiplets recombination by disassembly/reassembly in each sample. Since the $\tan \delta$ peak was observed at the higher temperature in the curve of i-SIS(Ba) than i-SIS(Na), the relaxation mode of i-SIS(Ba) is expected to be slower than that of i-SIS(Na), supporting the discussion about the frequency sweep measurements. 


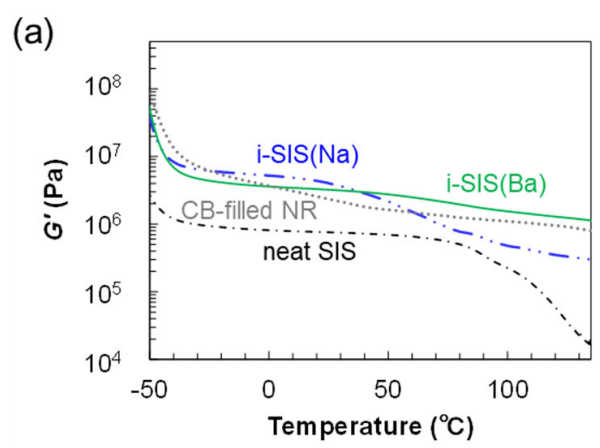

(b)

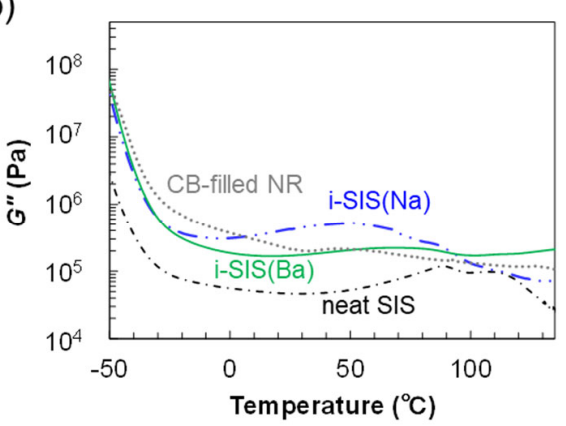

(c)

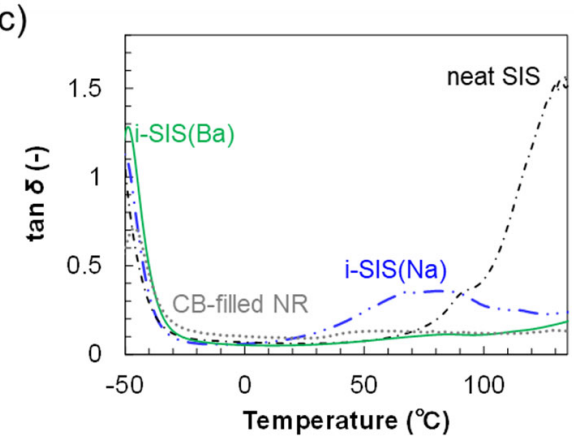

Figure S9. The temperature dependence of (a) $G^{\prime}$, (b) $G$ "' and (c) $\tan \delta$ acquired by dynamic mechanical tests for neat $\mathrm{SIS}^{1}, \mathrm{CB}-$ filled NR, i-SIS(Na) ${ }^{1}$ and i-SIS(Ba). 


\section{Energy-time curves acquired by drop weight impact tests.}

Figure S10 shows energy-time curves acquired by drop weight impact tests for neat SIS, CB-filled NR, i-SIS(Na), and i-SIS(Ba). The drop weight impact energy $\left(E_{\mathrm{I}}\right)$ is the maximum energy value in the energy-time curve that is a plot of the energy applied to the test specimen against time after the striker hits the test specimen. The repeating bumps and dents on the curves after the first peaks derive from the mechanical buffer device to prevent the striker from hitting the specimen again.
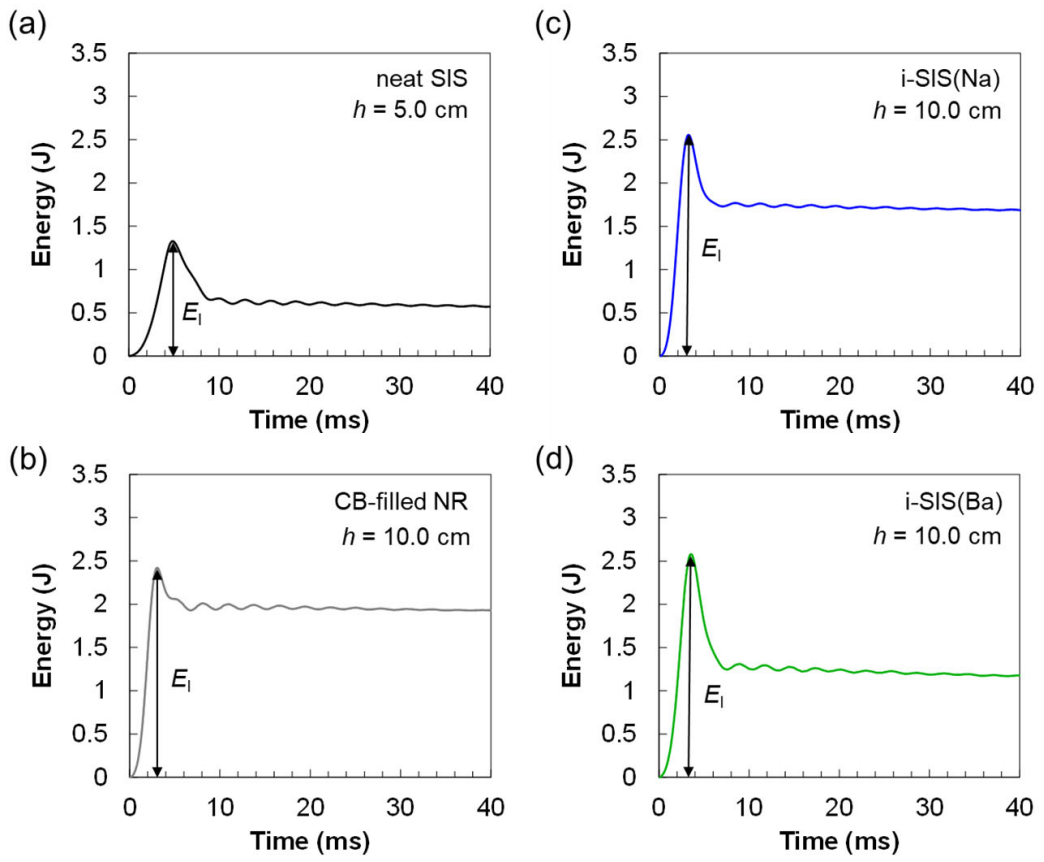

Figure S10. Energy-time curves acquired by drop weight impact tests at $h=5.0 \mathrm{~cm}$ or $10.0 \mathrm{~cm}$ for (a) neat SIS, (b) CB-filled NR, (c) i-SIS(Na), and (d) i-SIS(Ba). 


\section{Optical microscopy images of the test specimens after the drop weight impact tests.}

Figure S1 1 compares optical microscopy images of the test specimen of CB filled-NR after the drop weight impact tests. Obviously, no irreversible impact damage, such as cracks, were seen on the left image, whereas irreversible damage is observed on the right one, and the damage could not be self-repaired even if left for 1 week at room temperature. Therefore, the irreversible damage

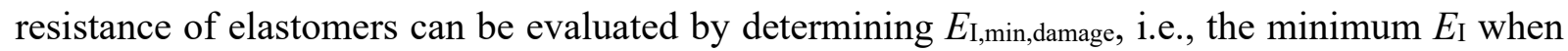
damage is caused to the test specimen. Similarly, Figure S11b, c, and d also compare optical microscope images of the test specimen of i-SIS(Na), GFRP, and i-SIS(Ba) after the drop weight

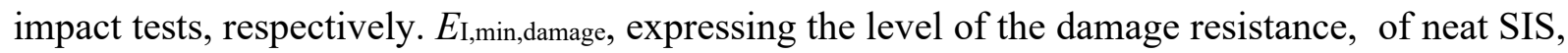
CB-filled NR, i-SIS(Na), GFRP, and i-SIS(Ba) is summarized in Table S1.

(a)

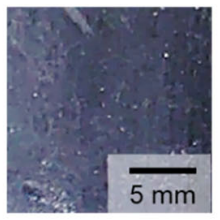

(c)

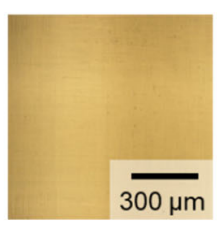

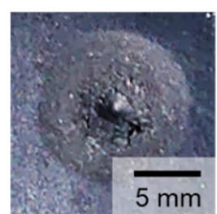

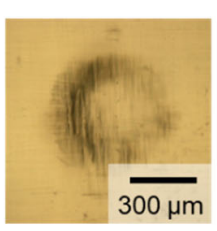

(b)

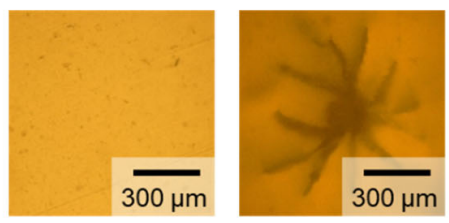

(d)

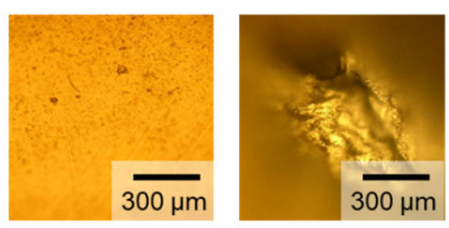

Figure S11. Optical microscopy images of the test specimens after drop weight impact tests for (a) CB-filled NR, (b) i-SIS(Na), (c) GFRP, and (d) i-SIS(Ba). Left image in each part of the figure exhibits the specimen without any irreversible damage after the tests $(h=35.0,50.0,0$, and 80.0 $\mathrm{cm}$, respectively), whereas right image in each part of the figure shows the specimen with irreversible damage after dropping the striker $(h=40.0,55.0,5.0$, and $85.0 \mathrm{~cm}$, respectively). 


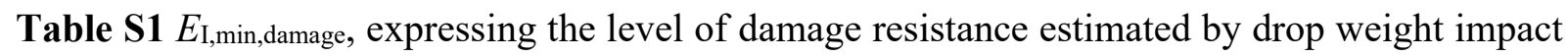
tests

\begin{tabular}{ccc}
\hline Sample & $E_{\mathrm{I}, \text { min,damage }}{ }^{\mathrm{a}}(\mathrm{J})$ & $h^{\mathrm{b}}(\mathrm{cm})$ \\
\hline Neat SIS & 1.89 & 7.5 \\
CB-filled NR & 9.99 & 40.0 \\
i-SIS(Na) & 14.2 & 55.0 \\
GFRP & 1.20 & 5.0 \\
i-SIS(Ba) & 21.6 & 85.0
\end{tabular}

${ }^{a}$ Minimum impact energy such that irreversible impact damage, such as cracks or dents, occurs to the specimen. The tests were performed using a rod-like striker with a $16 \mathrm{~mm}$ rounded head (mass $2.709 \mathrm{~kg}$ ) at $23^{\circ} \mathrm{C}$ and $50 \% \mathrm{RH}$. ${ }^{b}$ Minimum height position of the striker for a drop weight impact test such that irreversible damage occurs to the specimen 


\section{Mechanical properties of the GFRP.}

Tensile properties of the epoxy resin-based GFRP (PGE-6635, Ryoden Kasei Co., Ltd) were evaluated by conducting tensile test at ambient temperature with a $50 \mathrm{~mm}$ initial specimen distance between jigs using the INSTRON 5582. The dimension of the test specimen was a thickness of $\sim 4$ $\mathrm{mm}$, a width of $\sim 10 \mathrm{~mm}$ and a length of $\sim 80 \mathrm{~mm}$ (Figure $\mathrm{S} 12 \mathrm{a}$ ). The elongation rates used was $0.017 \mathrm{~mm} \mathrm{~s}^{-1}$, and therefore the $\dot{\varepsilon_{0}}$ was $3.3 \times 10^{-4} \mathrm{~s}^{-1}$. The tensile stress-strain curve of the GFRP is shown in Figure S12b. Table S2 also summarizes the tensile properties of the GFRP. Charpy unnotched impact strength of the GFRP was also measured by using an impact tester (INSTRON 9950), where a velocity of the hammer at the impact to the specimen was $3.8 \mathrm{~m} \mathrm{~s}^{-1}$. The dimension of the test specimen of the GFRP for the Charpy unnotched impact test was the same as the one for the tensile test. Charpy unnotched impact strength of the GFRP is also shown in Table S2, which was 10 times higher than that of PMMA. ${ }^{4}$

(a)

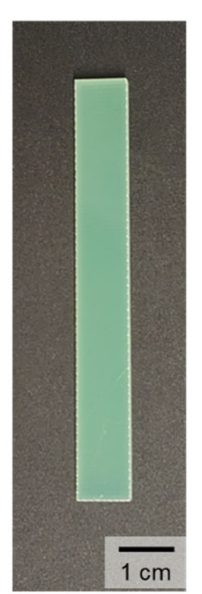

(b)

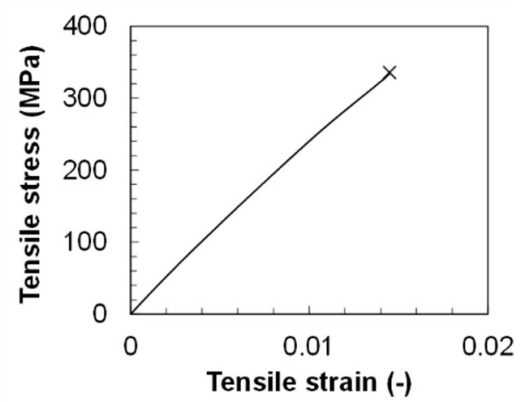

Figure S12. (a) Photo of the specimen of GFRP for the tensile test and the Charpy unnotched impact test. (b) Tensile stress-strain curves of GFRP. 
Table S2 Mechanical properties of the GFRP

\begin{tabular}{|c|c|c|c|c|c|c|}
\hline Manufacturer & $\begin{array}{l}\text { Product } \\
\text { code }\end{array}$ & $\begin{array}{c}\text { Standard number } \\
\text { used for } \\
\text { manufacturing }\end{array}$ & $\begin{array}{c}E_{\mathrm{Y}}^{\mathrm{b}} \\
(\mathrm{MPa})\end{array}$ & $\begin{array}{c}\sigma_{\max }{ }^{\mathrm{c}} \\
(\mathrm{MPa})\end{array}$ & $\begin{array}{c}\varepsilon_{\max }{ }^{d} \\
(-)\end{array}$ & $\begin{array}{l}\text { Charpy unnotched } \\
\text { impact strength } \\
\left(\mathrm{J} \mathrm{cm}^{-2}\right)\end{array}$ \\
\hline $\begin{array}{l}\text { Ryoden Kasei } \\
\text { Co., Ltd. }\end{array}$ & PGE-6635 & $\begin{array}{c}\mathrm{JIS}^{\mathrm{a}} \mathrm{K} 6912 \text { EL- } \\
\text { GEM }\end{array}$ & $27 \times 10^{3 \mathrm{e}}$ & $334^{\mathrm{f}}$ & $0.014^{\mathrm{g}}$ & $10.8^{\mathrm{h}}$ \\
\hline
\end{tabular}

${ }^{a}$ Abbreviation for Japanese Industrial Standards. ${ }^{b}$ Young's modulus. ${ }^{\mathrm{c}}$ Tensile strength. ${ }^{\mathrm{d}}$ Elongation at break. ${ }^{\mathrm{e}} E_{\mathrm{Y}}$ of a typical plastic PMMA has been estimated to be $3.1 \times 10^{3} \mathrm{MPa} .{ }^{5}{ }^{\mathrm{f}} \sigma_{\max }$ of PMMA has been estimated to be $54 \mathrm{MPa} .{ }^{5}{ }^{\mathrm{g}} \mathcal{E}_{\max }$ of PMMA has been estimated to be $0.0042 .{ }^{5}$ hThe Charpy unnotched impact strength of PMMA has been estimated to be $1.1 \mathrm{~J} \mathrm{~cm}^{-2} .4$

\section{References}

1. Kajita, T.; Tanaka, H.; Noro, A.; Matsushita, Y.; Nozawa, A.; Isobe, K.; Oda, R.; Hashimoto, S. Extremely tough block polymer-based thermoplastic elastomers with strongly associated but dynamically responsive noncovalent cross-links. Polymer 2021, 217, 123419.

2. Miwa, Y.; Taira, K.; Kurachi, J.; Udagawa, T.; Kutsumizu, S. A gas-plastic elastomer that quickly self-heals damage with the aid of $\mathrm{CO}_{2}$ gas. Nat. Commun. 2019, 10 (1), 1828.

3. Eisenberg, A.; Hird, B.; Moore, R. B. A New Multiplet-Cluster Model for the Morphology of Random Ionomers. Macromolecules 1990, 23 (18), 4098-4107.

4. Heim, P.; Wrotecki, C.; Avenel, M.; Gaillard, P. High Impact Cast Sheets of Poly(methyl methacrylate) with Low Levels of Polyurethane. Polymer 1993, 34 (8), 1653-1660.

5. Lee, D. C.; Jang, L. W. Preparation and Characterization of PMMA-Clay Hybrid Composite by Emulsion Polymerization. J. Appl. Polym. Sci. 1996, 61 (7), 1117-1122. 